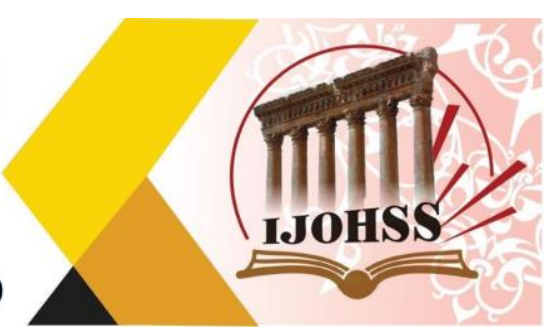

\title{
مرحلة النظرية المعيار في المدرسة التوليدية التحويلية وحضور المعنى
}

\author{
أ.م.د. حسام عدنان الياسري الآدب ـ جامعة القادسية ـ العراق مصطقى هاتف بريهي
}

الملخص

إن أهمية المعنى في الدرس اللساني لم تكن غائبة عن فكر تشومسكي، بالرغم من أنه قد أغفلها في المرحلة الأولى في بناء نظريته، في كتاب البنى النحوية، لأنه قد عني بنأسيس نحو شكلي نركيبي قائم على أسس منطقية رياضية يعنى بالشكل و التركيب من دون الالتفات للمعنى، ومن ثم اكتشف قصورا في تلك النظرية بإغفالها

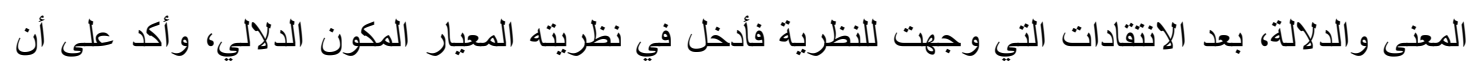
المعنى مثل التركيب يجب أن يخضع للتحليل العلمي الدقيق و إن الدلالة يجب أن تدرج في التحليل النحوي بوصفها جزءاً مكملاً لا يمكن الاستغناء عنه. فالجمل تتألف من مكونات ثلاث هي: المكون الفونولوجي و المكون التركيبي

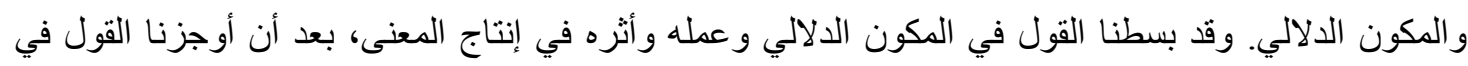
نشأة النظرية المعيار و المبادئ العامة التي تضمنتها، لنخلص من ذلك إلى أن تشومسكي قد أدخل المعنى في دائرة اهتمامه بعد أن أهمله من قبل.

الكلمات المفتاحية: النظرية المعيار ، المدرسة التوليدية التحويلية، حضور المعنى. 


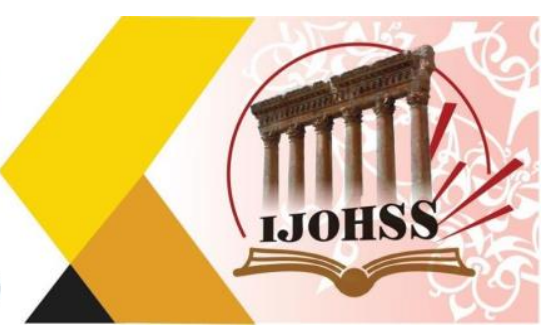

\title{
Theoretical Stage the Standard in the Transformative Obstetric School and the Presence of Meaning
}

\author{
Assis. Prof. Dr. Husam Adnan Al-Yasiri \\ Mustafa Hatef Buraihi \\ College of Arts - University of Qadisiyah - Iraq
}

\begin{abstract}
The importance of meaning in the tongue lesson was not absent from Chomsky's thought, although he had urged her in the first phase in building his theory, in the grammatical structures, because he had been established for a compact formal based on a sports logical basis The two components are composed of three: the phonological component, component and semantic component. We have strictly stated in the semantic component and its work and its impact on the production of the meaning, after we summarized the mandate of theoretical and general principles that ensured that Chomsky had entered the meaning in the circle of interest after he neglected.
\end{abstract}

Keywords: standard theory, transformational obstetric school, meaning presence. 
المجلة اللدولية اللملوم الأسانية والإجتاعياة

International Journal of Humanities and Social Sciences

website:www.ijohss.com

Email:editor@ijohss.com

ISSN: $2415-4822$

العدد (14) أغسطس 2020

Volume (14) August 2020

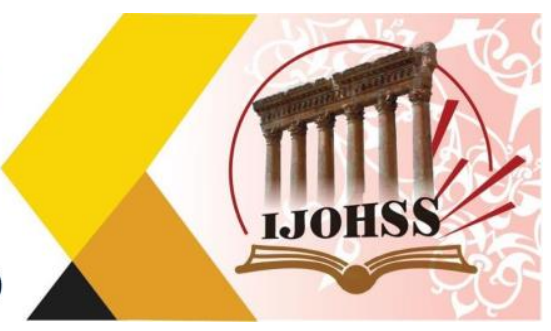

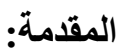

تعد النظرية التوليدية التحويلية من أهم النظريات اللسانية الحديثة التي تناولت الدرس اللساني بإطار علمي التياتي

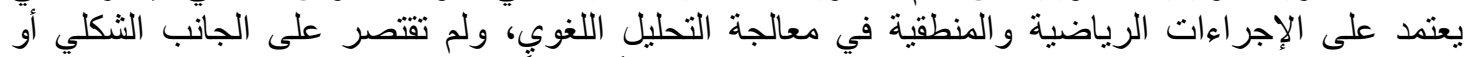

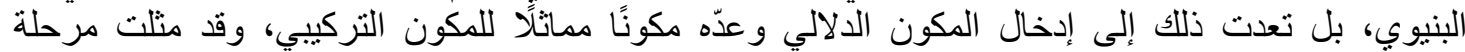

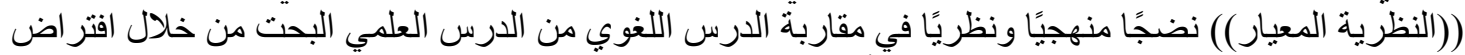

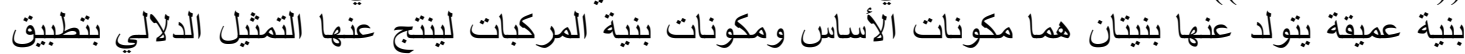

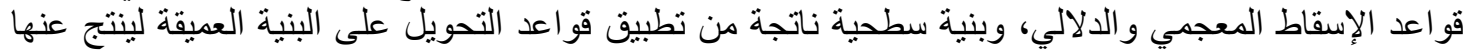

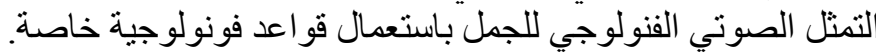

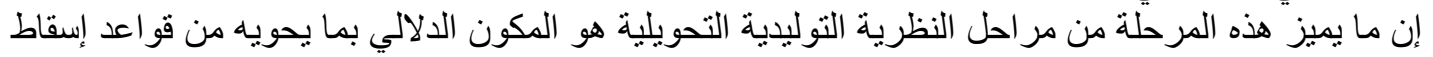

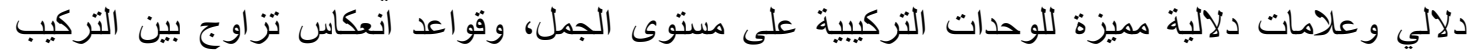

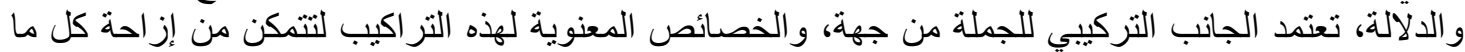
يتعارض مع التأويل الدلالي الفعلي للجمل المختلفة.

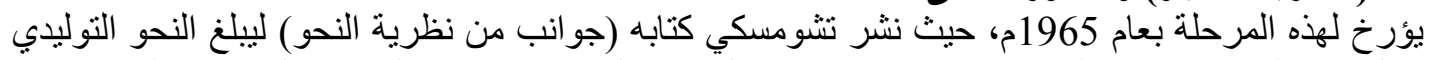

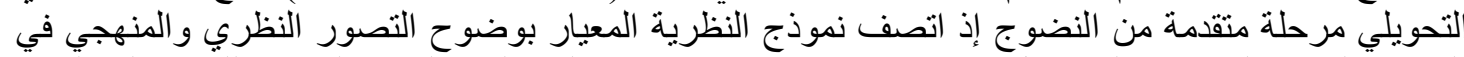

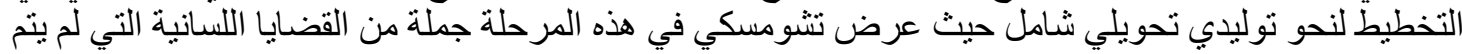

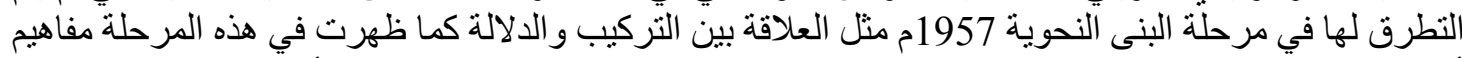

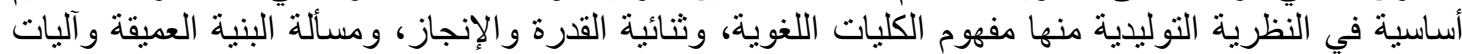

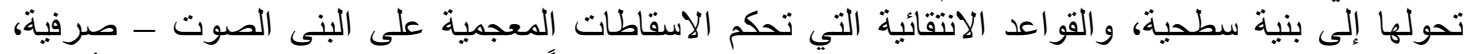

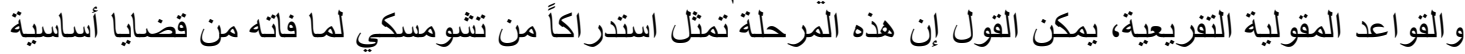
في مرحلة البنى النحوية، فقد تجاوز بهذه المرحلة الانتقادات الكبيرة التي وجهت إلى التى البنى النحوية، ولاسيما أهمال المعنى واستبعاد المكون الديالئي.

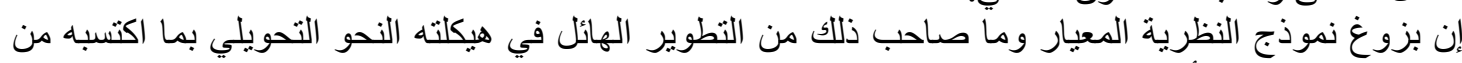

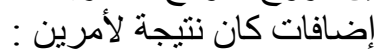
أولهما : قصور القو اعد النحوية النحان التوليدية في مرحلة 1957م في مجار اة التحليل اللغوي العلمي لأسباب تقنية تتعلق

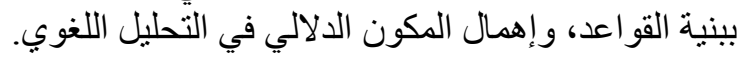

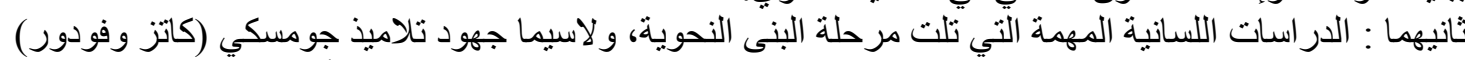

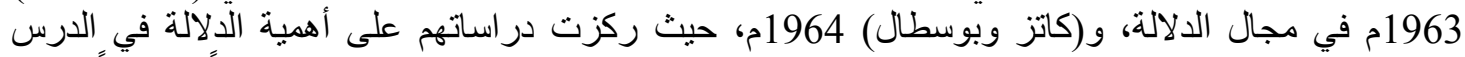

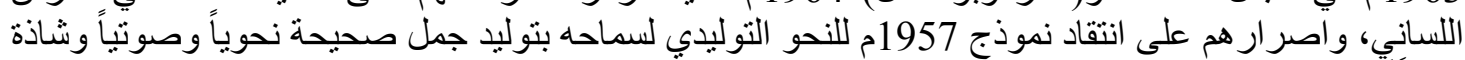

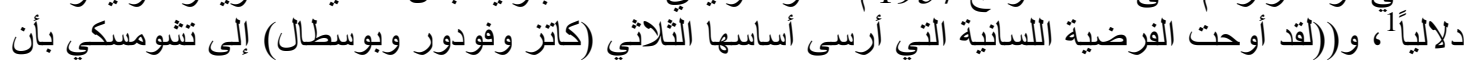

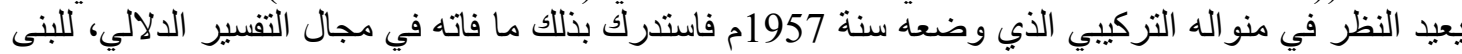

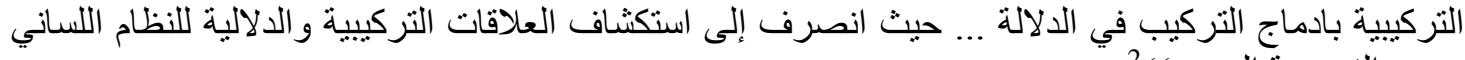
حسب الفرضية الجديدة)).

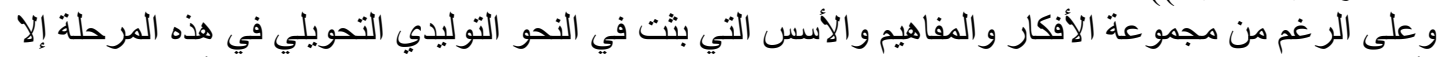

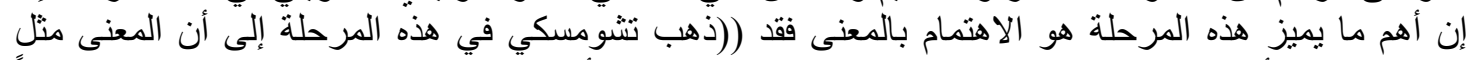

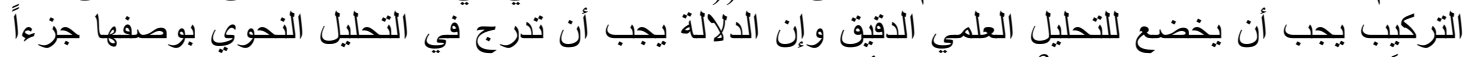

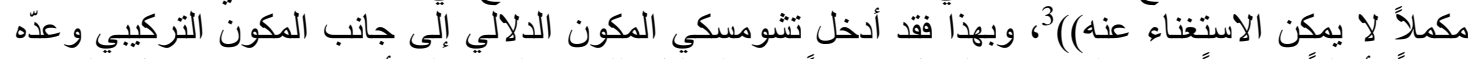

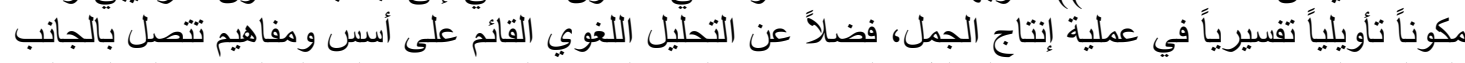

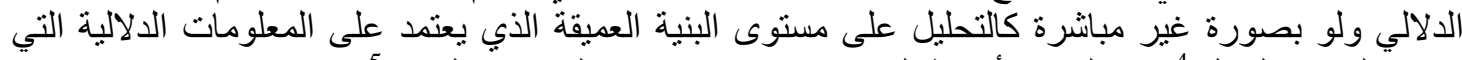

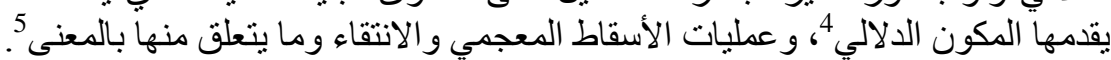

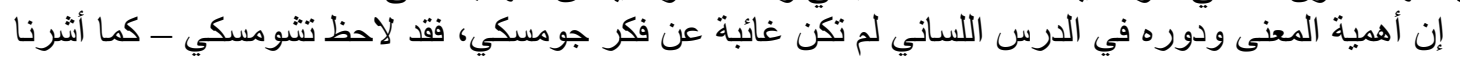

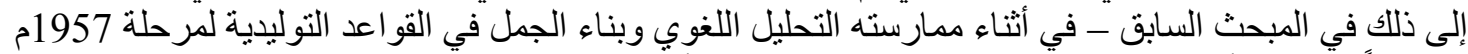

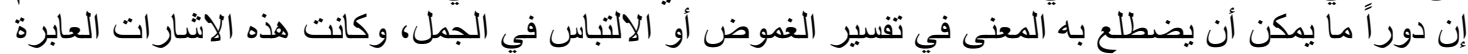


المجلة الحولية اللعلوم الآنسانية والإمتاعية

International Journal of Humanities and Social Sciences

website:www.ijohss.com

Email:editor@ijohss.com

ISSN: $2415-4822$

العدد (14) أغسطس 2020

Volume (14) August 2020

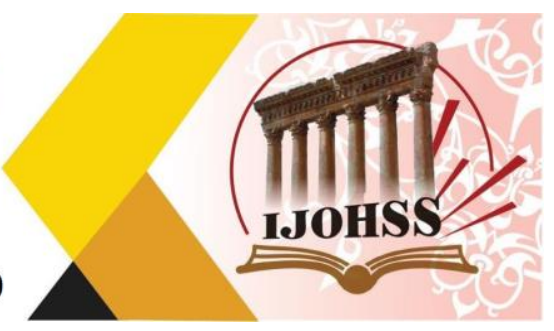

في كتاب "البنى النحوية" عن دور المعنى لا تمثل منهجاً صريحاً في تبني دور المعنى في التحليل اللغوي، إلا إنها

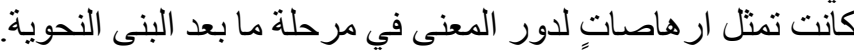

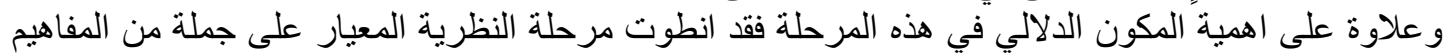
و الأفكار مثلت الدعامات و الأسس التي النبنت عليها قو اعد النحو التحويلي التوليدي، ويمكن إيجاز القول فيهاو وفق التقال

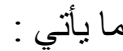

أولاً : أفتراض بنية اضئة عميقة :

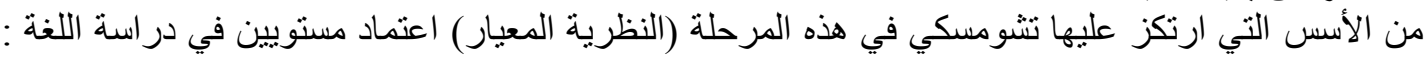

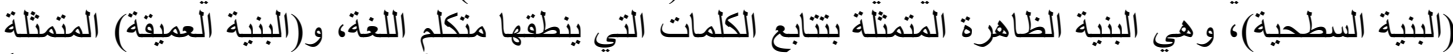

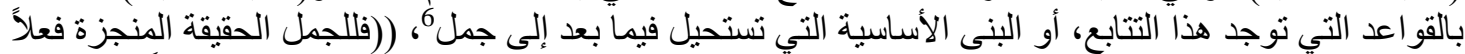

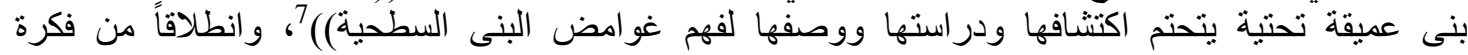

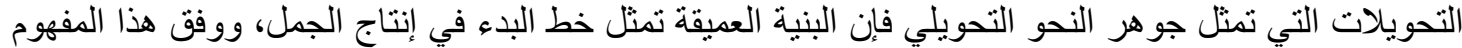

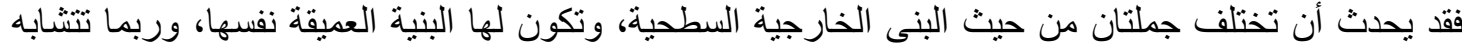
جملتان على مستوى السطح وتكون لهما بنيتان عميقتان مختلفتان كما في الجملتين :

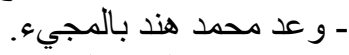
- سمح محمد لهند بالمجيء. ففي ظاهر هما متشابهتان على مستوى البنية السطحية، إلا إنها مختلفتان في البنية العميقة على النحو الآتي :

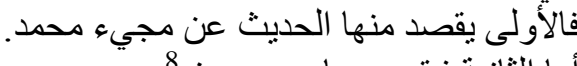

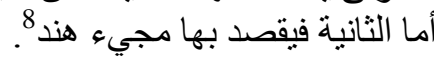
ثانياً : فرضية النحو فئدو الكلي (الكليات اللغوية)

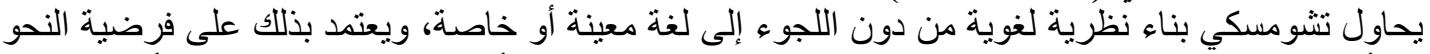

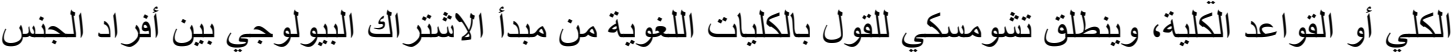

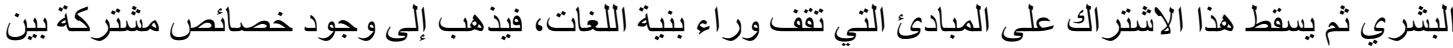

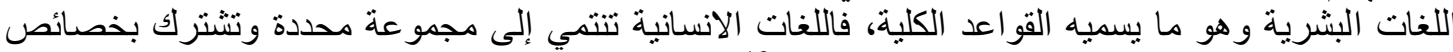

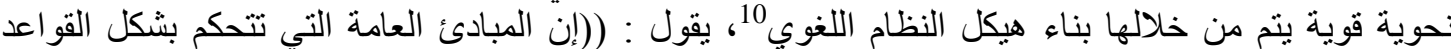

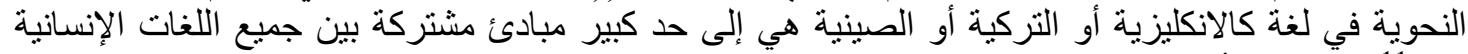

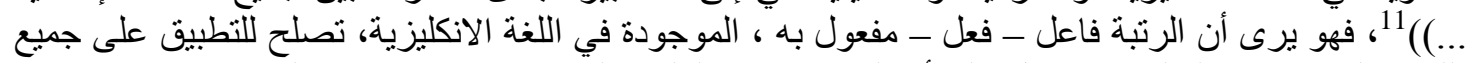

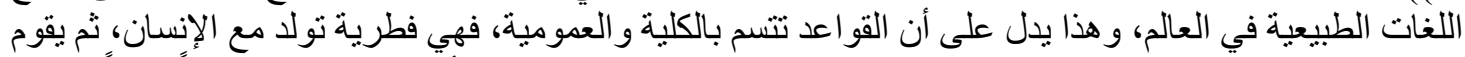

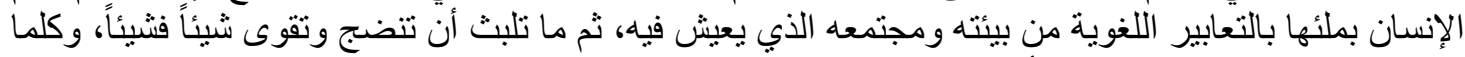

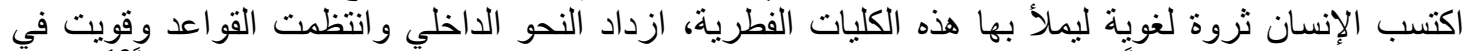

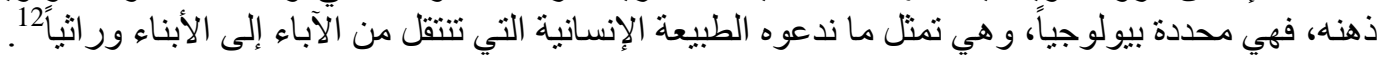

الكفاية K اللغوية والاداء الكلامي

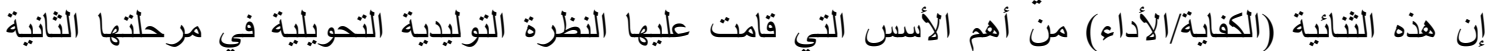

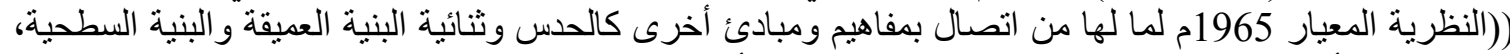

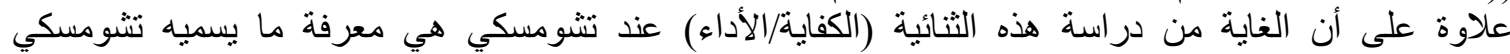

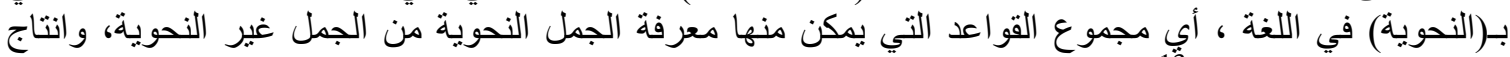

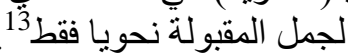

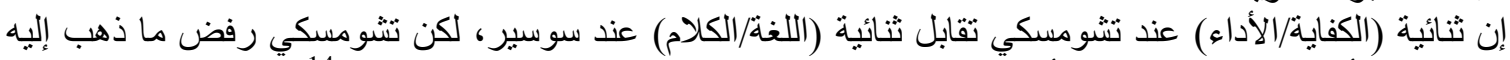

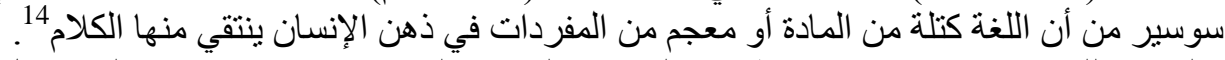

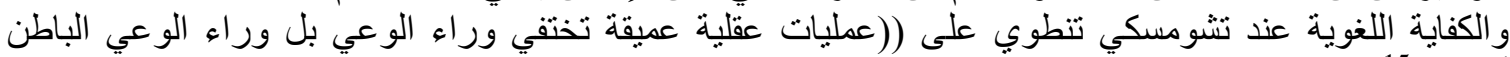

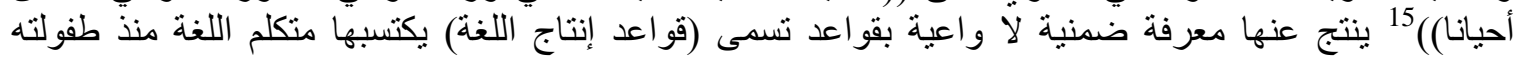

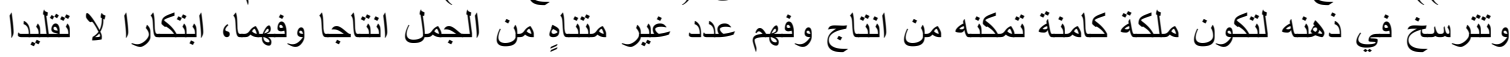




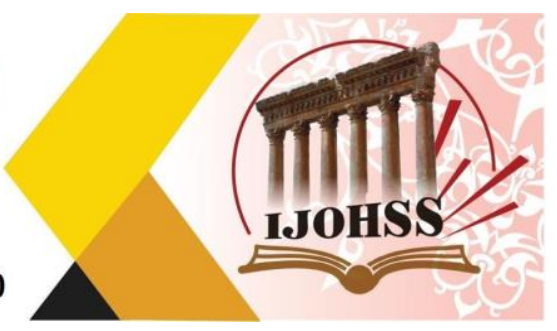

ساكنا، وتمكنه من التمييز بين الجمل السليمة نحويا من غيرها كما تمكن (المتكلم/السامع) المثالي من الربط بين

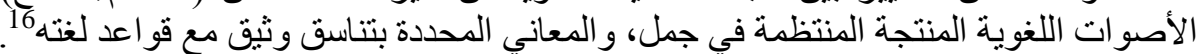

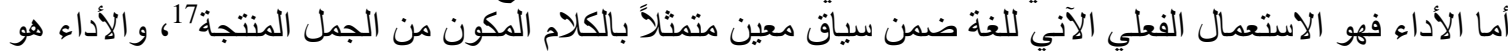

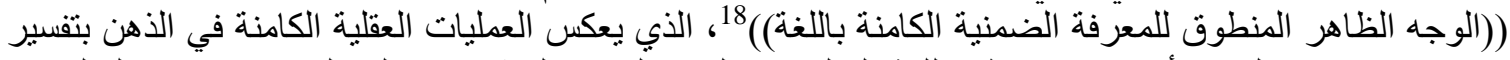

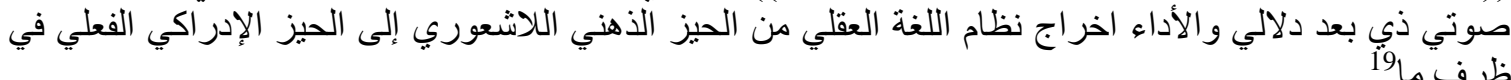

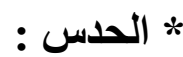
يرتبط مفهوم الحس ارتباطاً وثثقاً بالكفاية اللغوية، ويمكن القول إنه جزء منها، إذ إن الحدس هو مقدرة

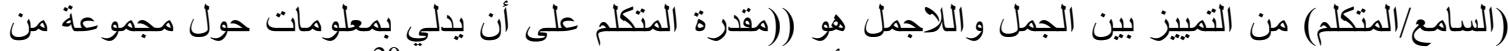

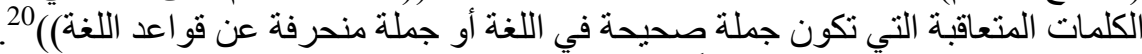

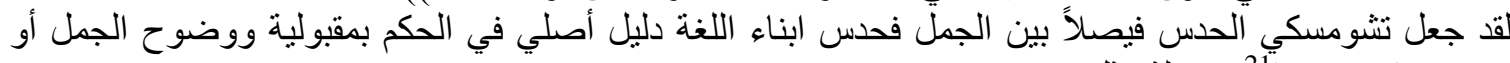

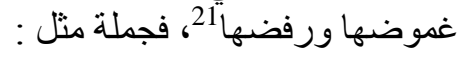

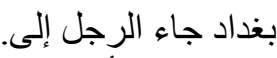

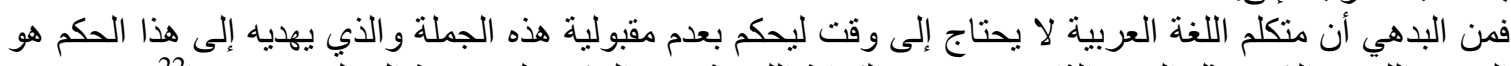

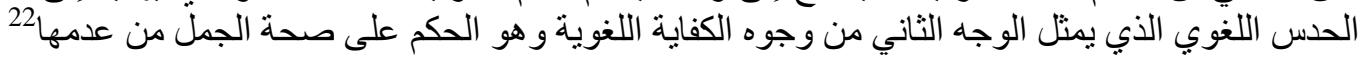

مكونات النحو في نموذج النظرية المعيار 1965

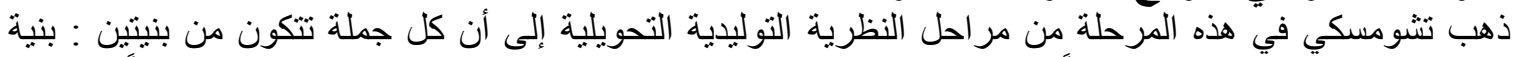

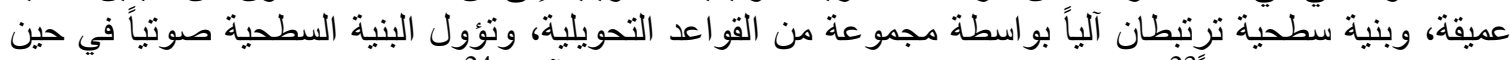

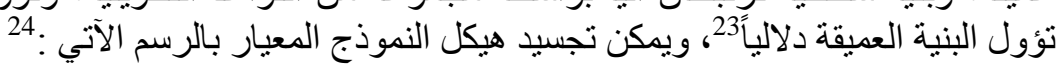

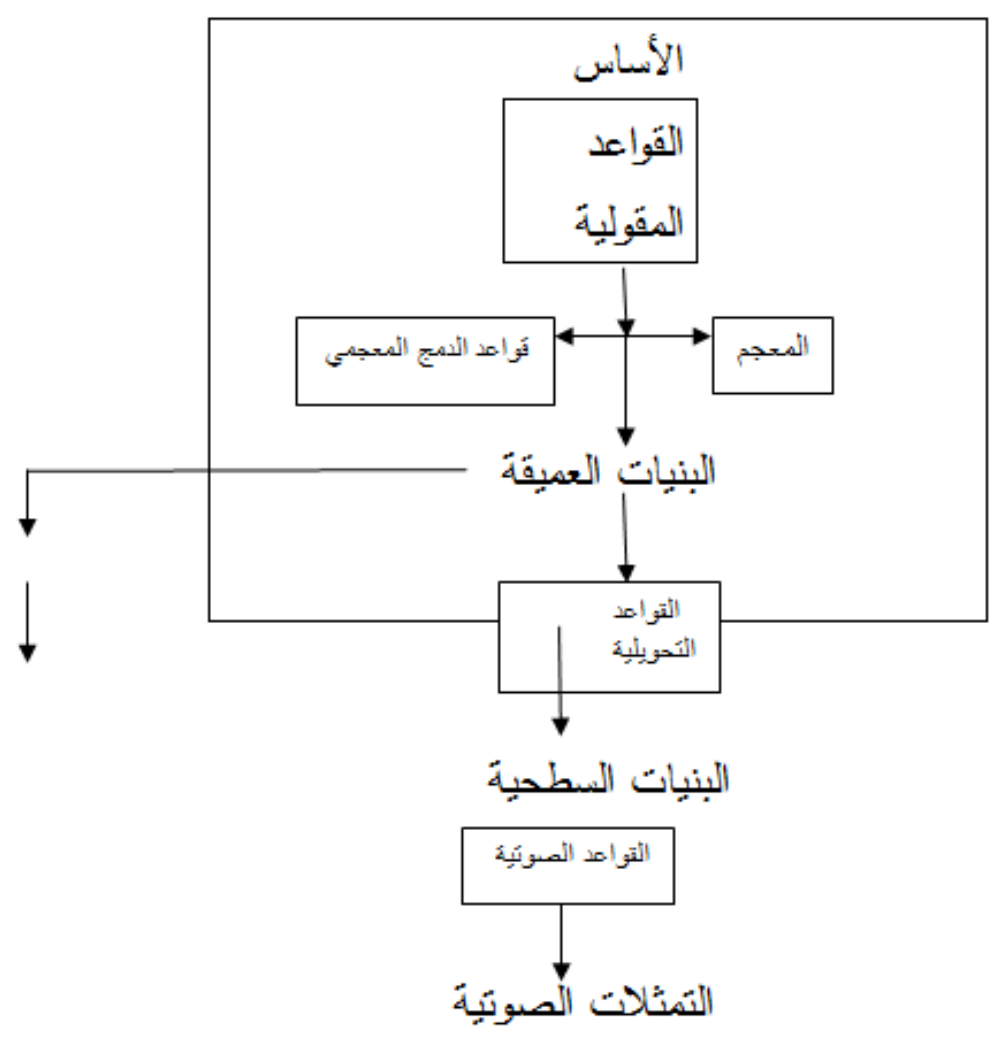




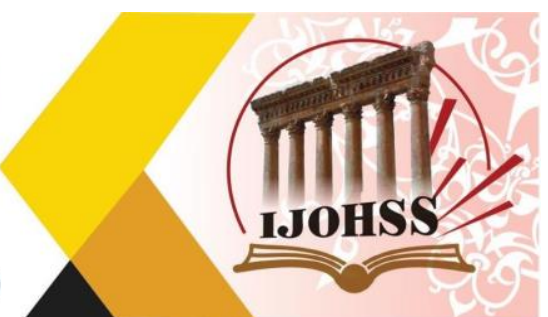

$$
\begin{aligned}
& \text { إن مكونات النحو في النموذج المعيار وكما هو في الثنكل هي ثلاثة مكونات25. } \\
& \text { 1- مكون تركيبي. } \\
& \text { 2- مكون صوتي. } \\
& \text { 3- مكون دلالي. }
\end{aligned}
$$

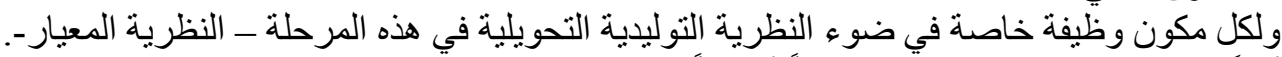

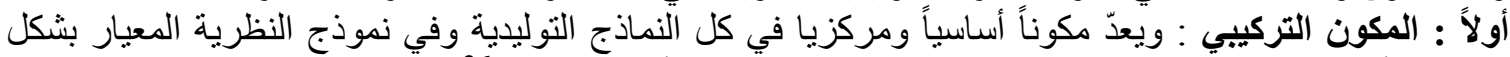

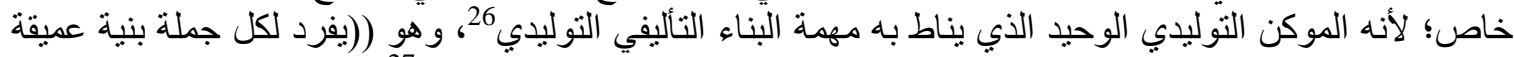

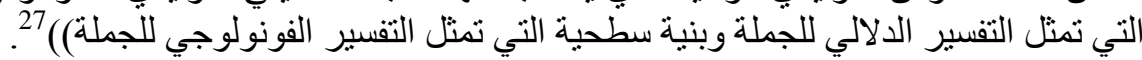

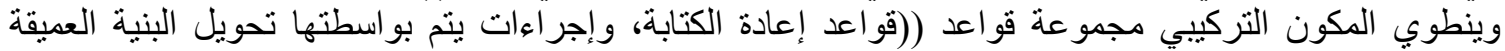

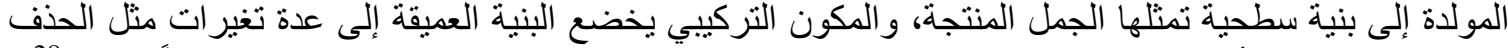

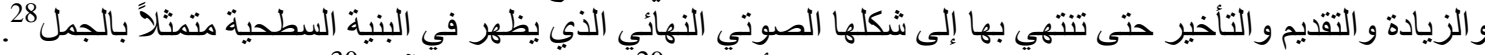

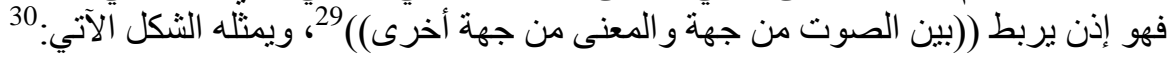

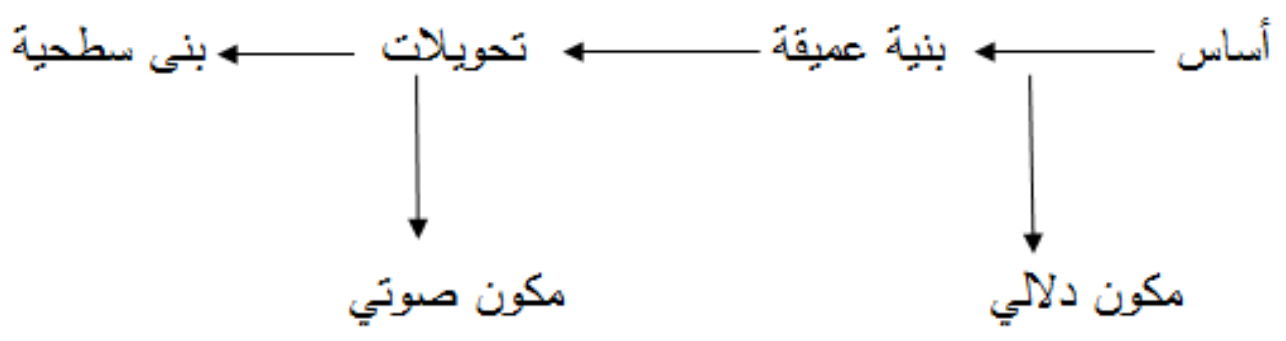

ثانيا: المكون الفونولوجي- الصرفي وينضوي في البنية السطحية، وهو الرئر ابط بين البنى السطحية و المستوى الصوتي حسب قو اعد خاصة بكل لغة. مثلا

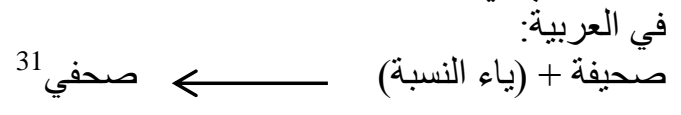

ثُالثا: المكون الدلالي و أهميته في هذه المرحلة (النظرية المعيار )

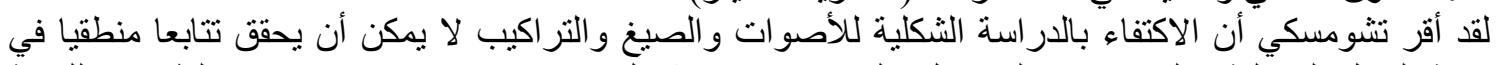

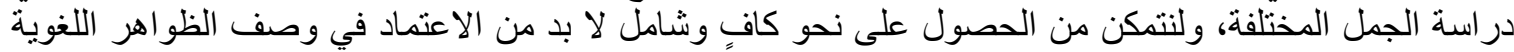

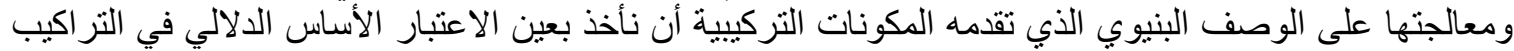

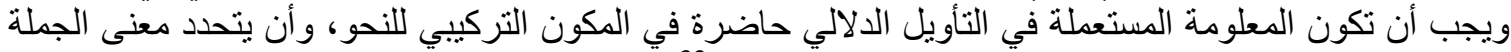

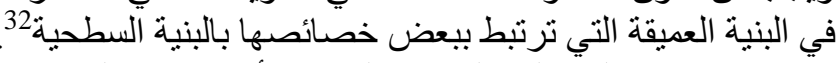
ويرى في هذه المرحلة (النظرية المعيار) أن استبعاد المعنى من التحليل التيل اللغوي اللساني يعني استحالة تفسير كثير

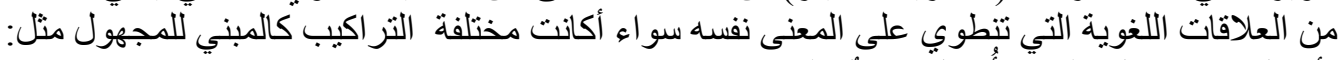

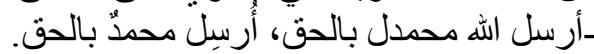

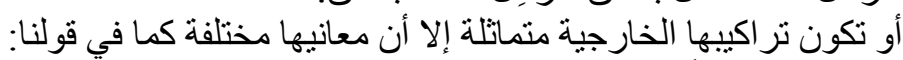
- ميريد أحصى عقلًا. عمرو أحصى مالًا.

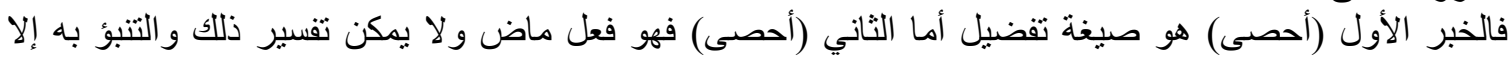
باللجو ء للعقل و المعنى لأن هذا ما يستلزم المعنى معرفته وتفسيره، كذلك قولنا: 


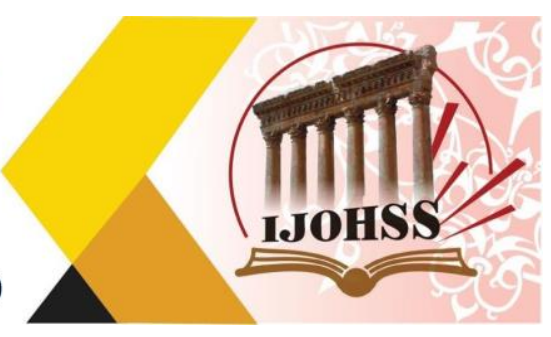

ـاقتناص الأسد نافع

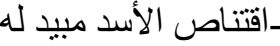

هاتين الجملتين لها نفس البنية التركيبية لكنهما يختلفان في المعنى.

وتكللت هذه المرحلة من مر احل النظرية التوليدية التحويلية (النظرية المعيار) بإضافة المكون الدالالي و عده مماثلًا للتركيب في عملية التحليل اللساني اللغوي 33

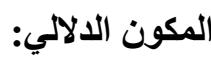

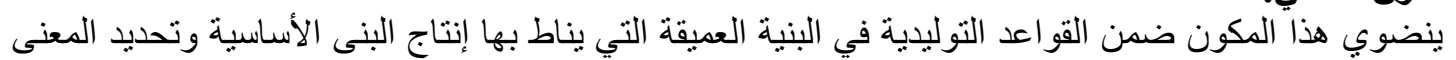

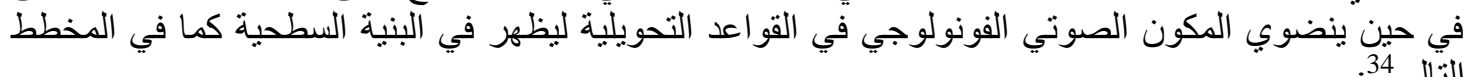
مكون أساس (قواعد بنية المركبات)
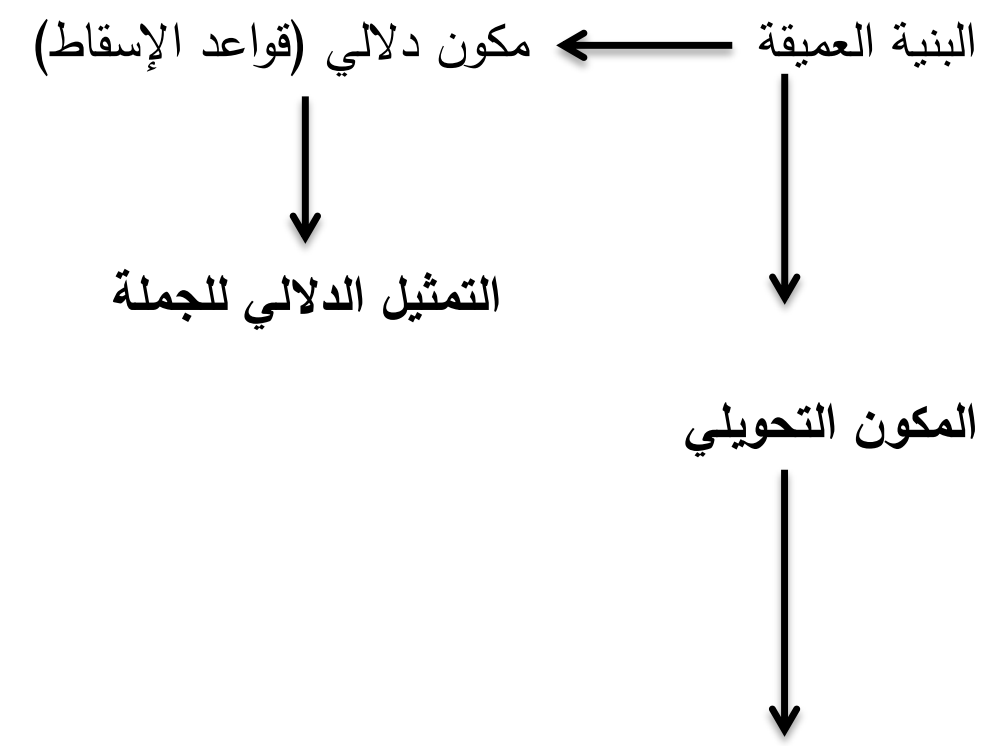

البنية السطحية
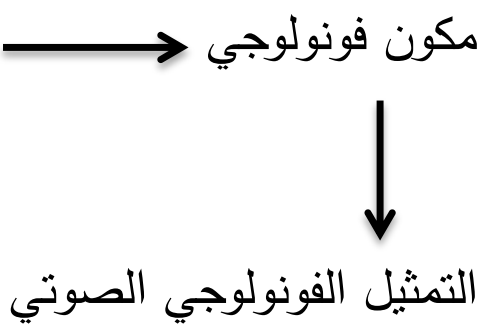


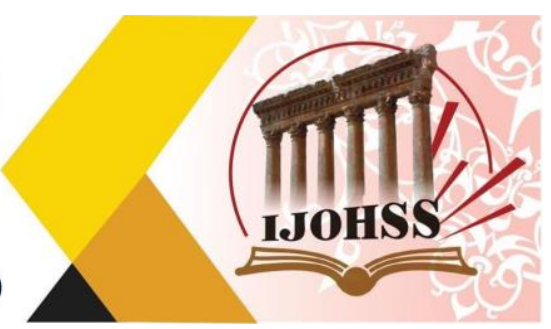

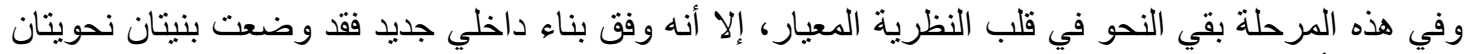

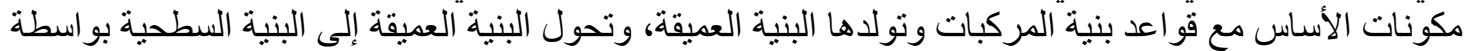
قو اعد التحويل وبهذا تولد مكونات الأساس أبنية مجردة، أما البنية السطحية فقط تطابق الجمل الصحيحة المعينة في اللغة:35.

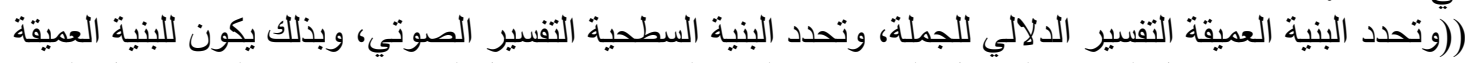

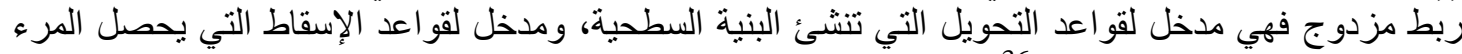

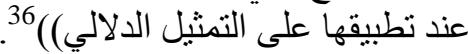
ويتألف المكون الدلالي من (المعجم- وقئ) واعد الانعكاس)، و المعجم يعطي لكل وحدة معنوية مجمو عة من الدلالات

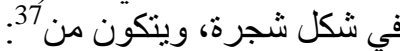

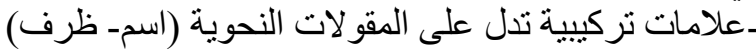
ـ علامات دلالية وهي مقو لات عات عامة مشتركة بين مجموعات من الوات الوحدات المعنوية مثل (عاقل- حي- مذكر-

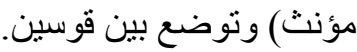

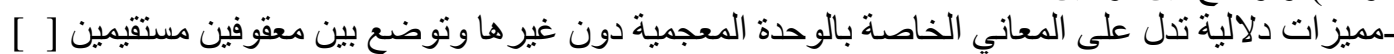

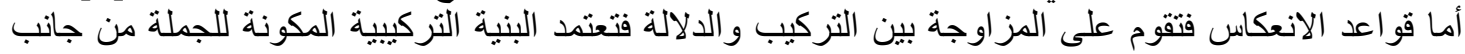

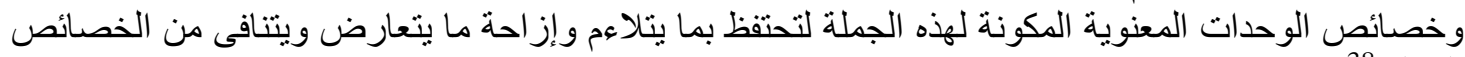
الدلالية

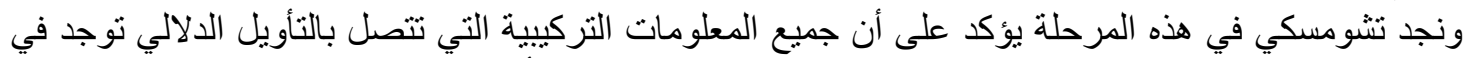

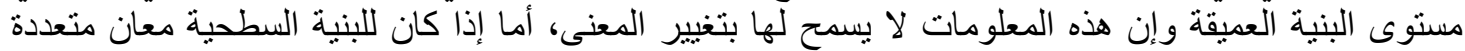

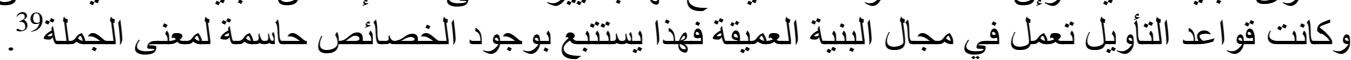

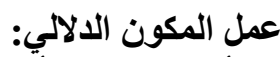

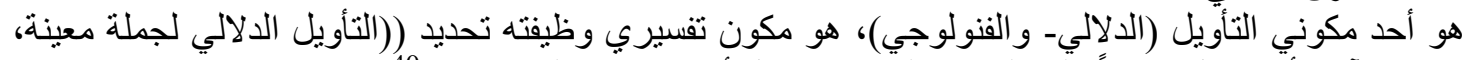

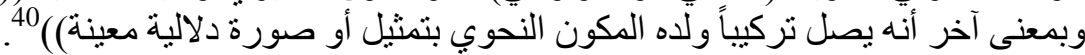

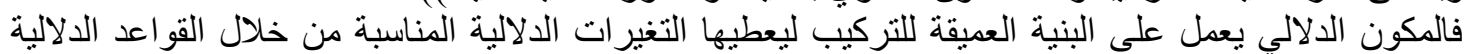

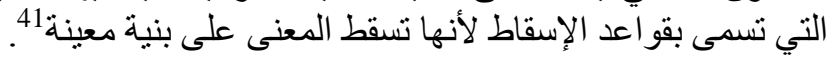
ويمكن تلخيص عمل المكون الدلالي في مرحلة النظرية المعيار بأنه يقرن كل مورفام من البنية اللغوية مع دلالته

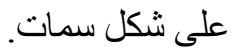
و هذا يتم عن طريق المدخلات المعجمية، ثم تقوم قو اعد التكرار الدالية بتوسيع هذه السمات من بعدها يأتي دور

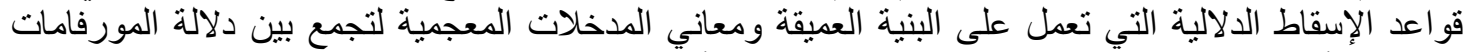

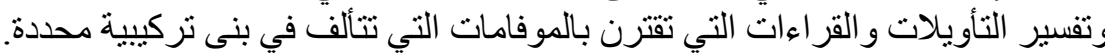

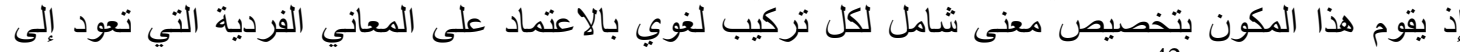

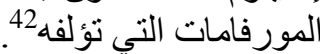

من خلال: الاستقراء الدقيق للنظرية التوليدية التحويلية في مرحلة (النظرية المعيار) توصل البحث إلى النتائج التالية: 1- بلغ النحو التوليدي التحويلي في هذه المرحلة مراحل متقدمة من النضوج النظري و المنهجي في بناء نحو

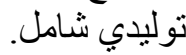
2- إن التطور الذي لحق النظرية التوليدية التحويلية لا سيما في مرحلة النظرية المعيار كان ور اءه أمران: الأول

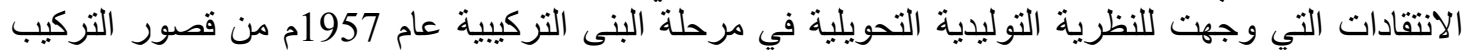

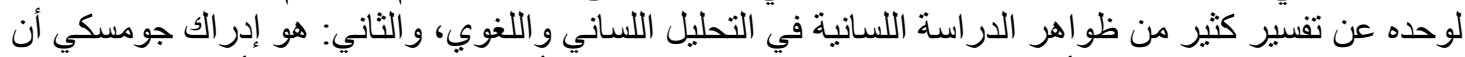

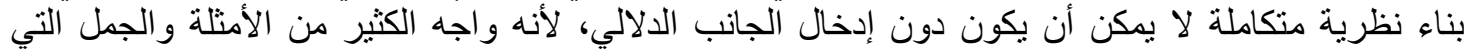

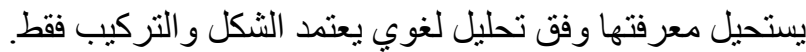


المجلة الحولية اللعلوم الآنسانية والإمتاعية

International Journal of Humanities and Social Sciences

website:www.ijohss.com

Email:editor@ijohss.com

أغسطس 2020

العدد (14)

ISSN: $2415-4822$

Volume (14) August 2020

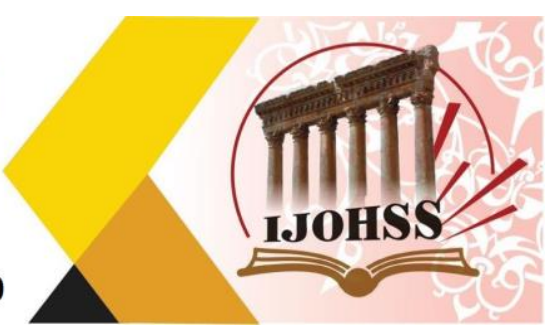

3- يعد المكون الدلالي في هذه المرحلة مكونا تأويلياً تفسيريًا ينضوي في البنية العميقة.

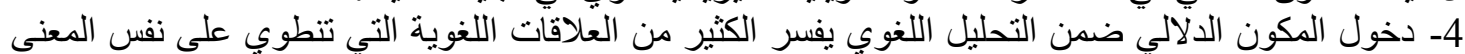
وسواء أكانت التر اكيب مختلفة أم منتابهة. 5- يعمل المكون الدلالي من خلال قواعد الإسقاط الدلالي انطلاقا من البنية العميقة ليعطي تفسير ادلاليا للتر اكيب

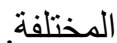

6- يعمل المكون الدلالي ضمن البنية العميقة معتمدا على قو اعد معجمية دقيقة أو قو اعد انعكاس (إسقاط) تز اولاوج

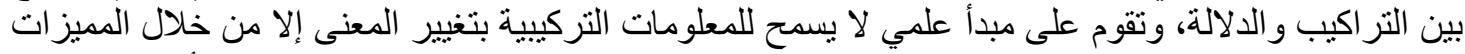
الدلالية الخاصة بالوحدة المعجمية لكل نركيب، وفق قلاكية قاعد الإسقاط الدلالي الذي ينتج عنه التأويل (التمثيل)

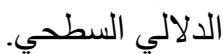
7- إن عمل النحو في مرحلة النظرية المعيار هو المزاوجة بين المستوى النحوي التركيبي والمستوى الدلالي للوصول إلى خصائص حاسمة لمعنى الجمل المختلفة ونوظيفها في التحليل اللغوي وفق نظرية النية نحو شامل.

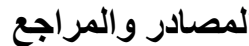

1- الألسنية التوليدية و التحويلية وقو التواعد اللغة العربية (النظرية الألسنية): د. ميشال زكريا، المؤسسة الجامعية للار اسات و النشر و التوزيع- بيروت، النالية الطبعة الثانية.

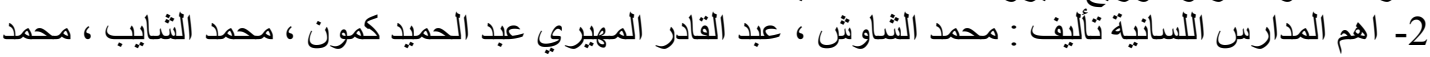

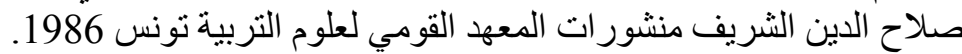

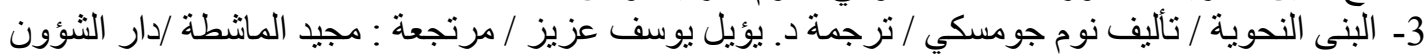

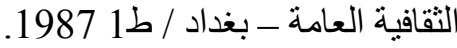
4- البنية العميقة في الدرس اللساني العربي المقولة و الاجر اء / الاء علي عبد الله العنبكي / دار نبيور للطباعة و النشر و التوزيع - العر اق / الطبعة الاولى العيف : 2014

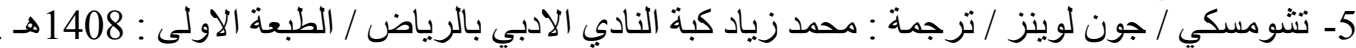

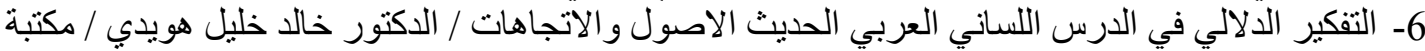

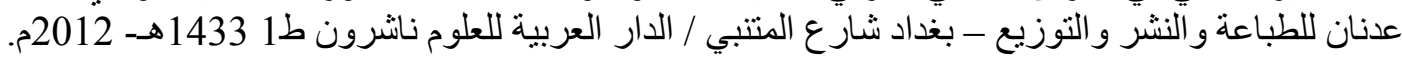

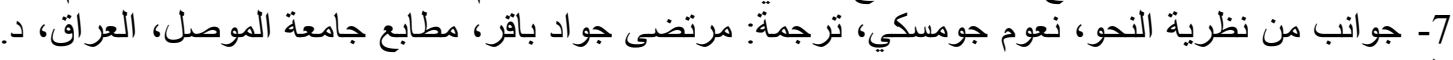

8- قو اعد النحو التحويلي بين نعوم تشومسكي والنحو العربي- دراسة تطبيقية في سورة آل عمران انموذجاـ رسالة ماجستير، عمر دومي، قسم اللغة والأدب العربي، كلية الآداب و اللغات، جامعة لئية محمد بوطياف، المسيلة.

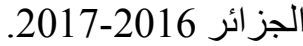
9- اللسانيات التوليدية من النموذج ما قبل المعيار الى البرنامج الادنوي: مفاهيم وامثلة ، الدكتور مصطفى غلفان الدان

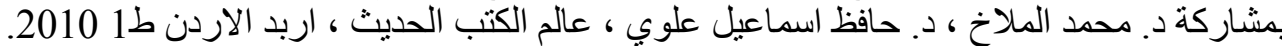

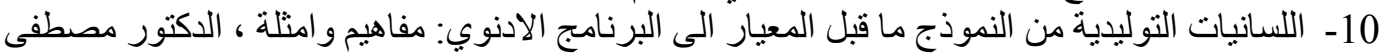

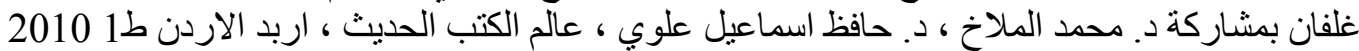

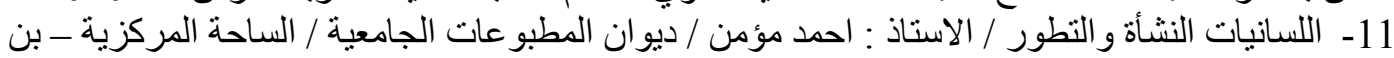

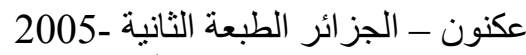

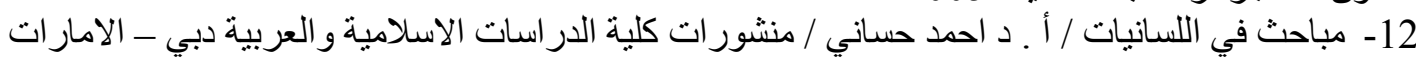
العربية المتحدة الطبعة الاولى : 2007 م.

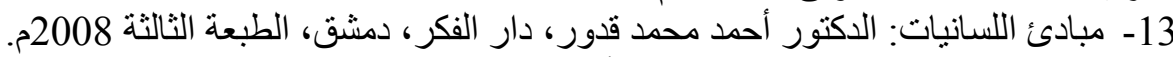

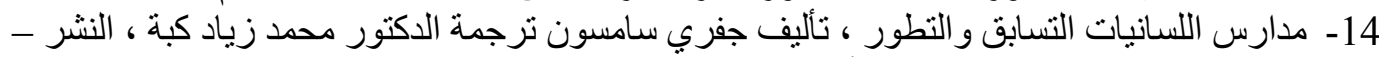

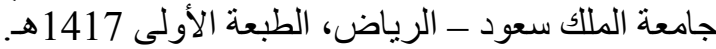
15- مدخل الى اللسانيات ، الدكتور محمد محمد يونس علي ، دار الكتاب الجديد المتحدة ، الطبعة الاولى بيروت 


\section{المجلة الحولية اللهلوم الآنسانية والإمتصاعية}

International Journal of Humanities and Social Sciences

website:www.ijohss.com

Email:editor@ijohss.com

أغططس 2020

العدد (14)

ISSN: $2415-4822$

Volume (14) August 2020

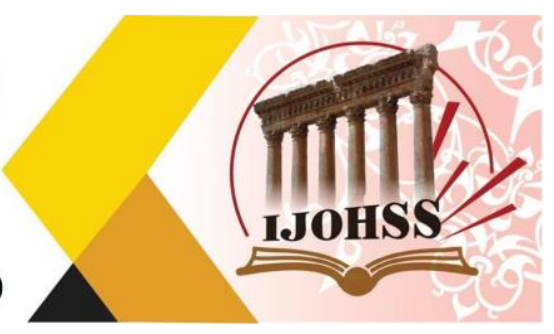

16- المسافة بين التنظير النحوي و التطبيق اللغوي ( بحوث في التفكير النحوي و التحليل اللغوي ) تأليف الاستاذ

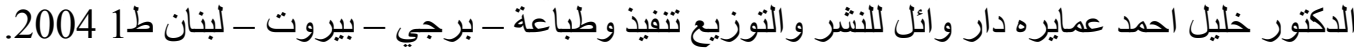

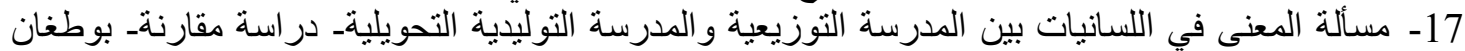

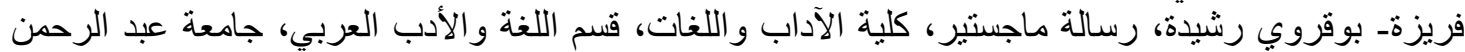

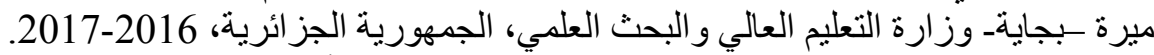

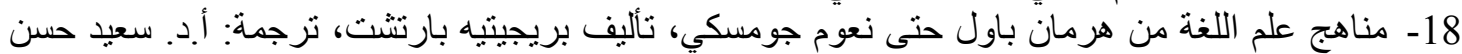

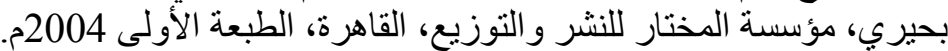
19- النحو التوليدي، قو البه النظرية و أنساقه الفرعية: د. رشيدة العُة العلوي كمال، دار كنوز المعرفة للنشر و التوزيع،

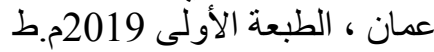
20- النحو العربي او الدرس الحديث بحث في المنهج / الدكتور عبده الراجدي/ دار النهضة العربية للطباعة

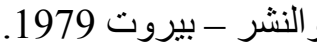

21- النظريات اللسانية الكبرى من النحو المقارن الى الذرائعية / ماري آن بافو جورج الياسرفاتي / ترجمة : محمد الر اضي / المنظمة العربية للترجمة / الطبعة الاولى : بيروت النئرئ ، اذار (مارس) 2012. 


\section{References}

1- Generative and transformational linguistics and the grammar of the Arabic language (linguistic theory): d. Michel Zakaria, University Foundation for Studies, Publishing and Distribution - Beirut, second edition.

2- The most important linguistic schools by: Muhammad Al-Shaoosh, Abdel-Qader Al-Muhairi Abdel-Hamid Kamoun, Mohamed Al-Shayeb, Mohamed Salah Al-Din Sharif Publications of the National Institute of Education Sciences Tunisia 1986.

3- Grammar Structures / Written by Nom Jomsky / Translated by Dr. Yoel Youssef Aziz / Returned: Majeed Al-Mashta / General Cultural Affairs House - Baghdad / 1st edition 1987.

4- The deep structure in the Arabic linguistic lesson, saying and doing / Alaa Ali Abdullah Al-Anbaki / Niebuhr House for Printing, Publishing and Distribution - Iraq / First Edition: 2014

5- Chomsky / John Lewins / translation: Muhammad Ziyad Kubba literary club in Riyadh / first edition: $1408 \mathrm{AH}$.

6- Semantic Thinking in the Modern Arabic Linguistic Lesson: Origins and Trends / Dr. Khaled Khalil Howaidi / Adnan Library for Printing, Publishing, and Distribution - Baghdad Al-Mutanabi Street / Arab House of Sciences Publishers I 11433 AH 2012 AD.

7- Aspects of grammar theory, Noam Jomsky, translation: Murtada Jawad Baqer, University of Mosul Press, Iraq, d. I.

8- The grammar of transformational grammar between Noam Chomsky and the Arab grammar - an applied study in Surat Al-Imran as a model - Master Thesis, Omar Dome, Department of Language and Arabic Literature, Faculty of Arts and Languages, University of Mohamed Boutiaf, Al-Messila - Algeria 2016-2017.

9- Obstetric linguistics from the pre-standard model to the Adawi program: concepts and examples, Dr. Mustafa Galfan with the participation of Dr. Muhammad alMalakh, d. Hafiz Ismail Alawi, Modern Book World, Irbid Jordan 1st ed. 2010.

10- Obstetric linguistics from the pre-standard model to the Adnoy program: concepts and examples, Dr. Mustafa Galfan with the participation of Dr. Muhammad alMalakh, d. Hafiz Ismail Alawi, Modern Book World, Irbid Jordan 1st ed. 2010

11- Linguistics, Origination and Evolution / Professor: Ahmed Moamen / University Publications Office / Central Square - Ben Aknoun - Algeria, Second Edition -2005

12- Investigative Linguistics / a. Dr. Ahmed Hassani / Publications of the College of Islamic and Arab Studies Dubai - United Arab Emirates First Edition: 2007 AD.

13- The Principles of Linguistics: Dr. Ahmad Muhammad Qaddour, Dar Al-Fikr, Damascus, third edition 2008.

14- Linguistics schools, race and development, written by Jeffrey Samson, translated by Dr. Muhammad Ziad Kubba, Publishing - King Saud University - Riyadh, first edition $1417 \mathrm{AH}$.

15- Introduction to Linguistics, Dr. Muhammad Muhammad Yunus Ali, United New Book House, First Edition Beirut - Lebanon.

16- The distance between grammar theory and linguistic application (research in grammatical thinking and linguistic analysis) by Professor Dr. Khalil Ahmed Amayreh 


\section{المجلة اللدولية اللملوم الأسانية والإمتاعياة}

International Journal of Humanities and Social Sciences website:www.ijohss.com Email:editor@ijohss.com ISSN: $2415-4822$
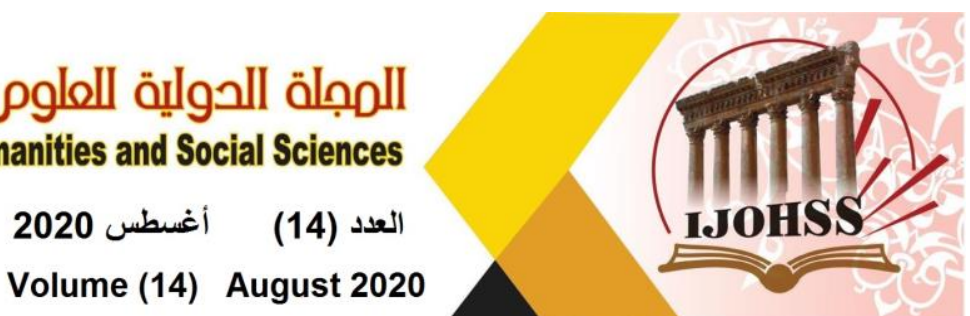

Dar Wael for Publishing and Distribution. Implementation and printing - Burji - Beirut - Lebanon, 1st edition 2004.

17- The question of meaning in linguistics between the distributive school and the transformative obstetric school - a comparative study - Boutagan Frieza - Boukraoui Rachida, Master Thesis, Faculty of Arts and Languages, Department of Language and Arabic Literature, Abdel Rahman Meera University - Bejaia - Ministry of Higher Education and Scientific Research, Algerian Republic, 2016-2017.

18- Curricula of Linguistics from Hermann Powell to Noam Jomsky, by Brigitte Barcht, translation: Prof. Dr. Saeed Hassan Beheiri, Al-Mukhtar Foundation for Publishing and Distribution, Cairo, the first edition of 2004.

19- Generative grammar, theoretical templates and sub-formats: d. Rachida Al-Olwi Kamal, Dar Konooz Al-Maarefa for Publishing and Distribution, Amman, first edition $2019 \mathrm{~m}$

20- Arabic grammar \and the modern lesson research in the curriculum / Dr. Abdo AlRajhi / Arab Renaissance House for Printing and Publishing - Beirut 1979.

21- Grand Linguistic Theories from Comparative Syntax to Arterialism / Mary-Ann Paveau, George Alyaservati / Translation: Muhammad Al-Radi / Arab Organization for Translation / First Edition: Beirut, March 2012.

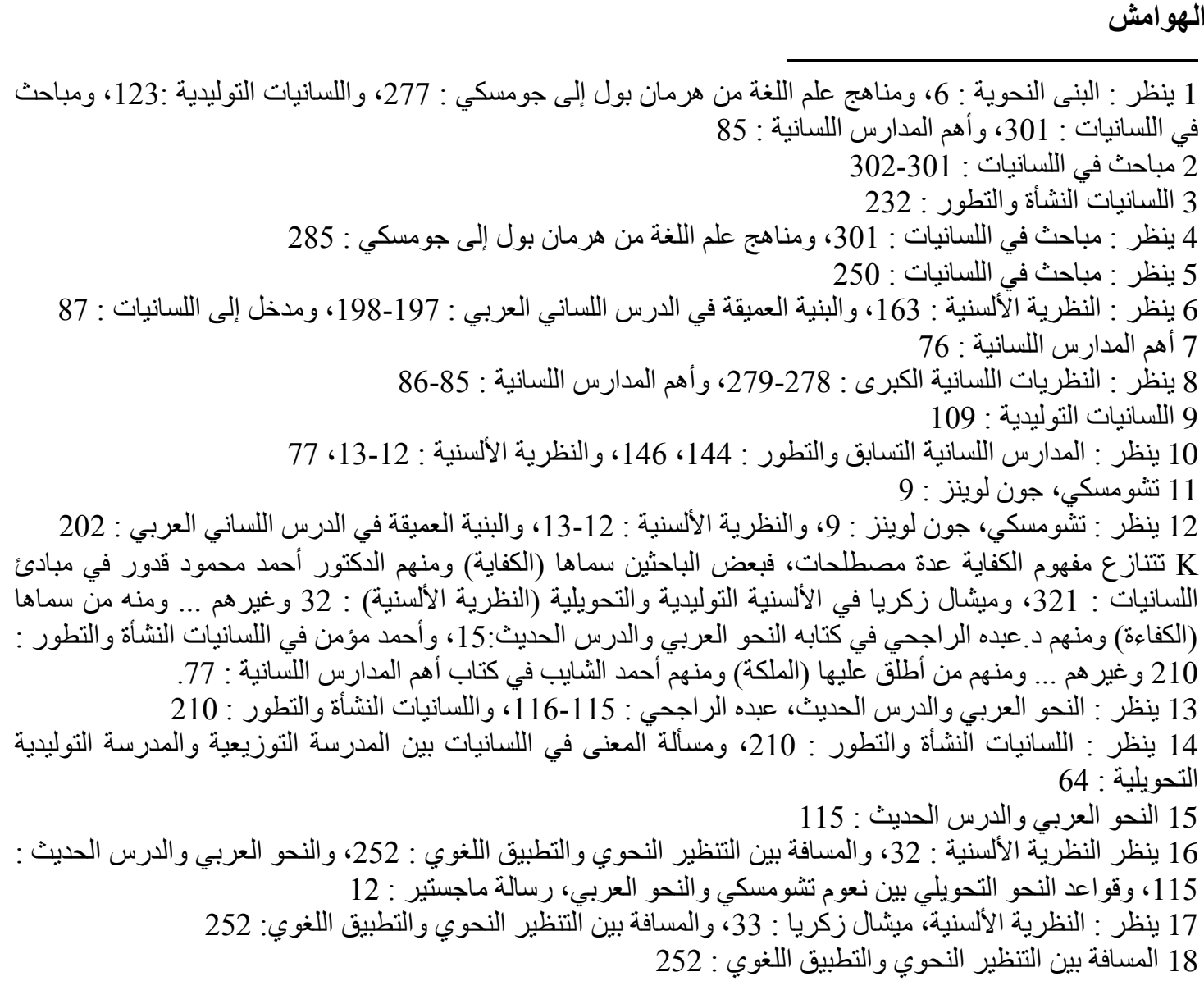


المجلة الحولية اللعلوم الآنسانية والإمتماعية International Journal of Humanities and Social Sciences website:www.ijohss.com Email:editor@ijohss.com العدد (14) أغسطس 2020 ISSN: $2415-4822$

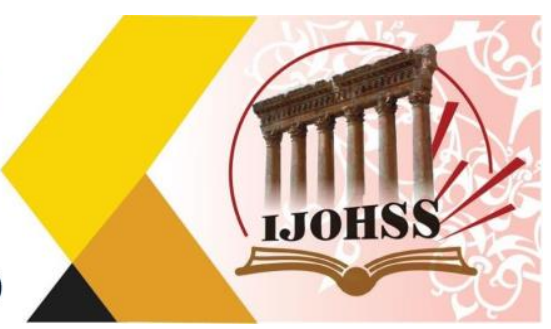

19 ينظر : النحو العربي والدرس الحديث: 115، واللسانيات النشأة والتطور : 210، وقو اعد النحو التحويلي بين نعوم

تشومسكي و النحو العربي : 12 : 12 38 : 20

21 ينظر : مبادئ اللسانيات، أحمد قدور : 215

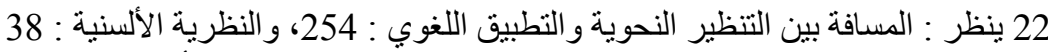

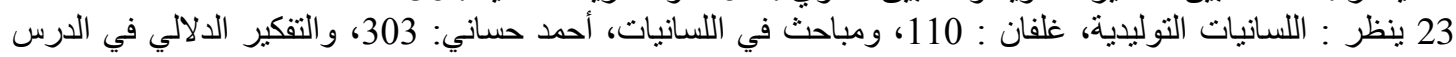
اللساني العربي الحديث، د.خالد خليل هويدي : 199 24 ينظر : اللسانيات التوليدية، غلفان : 110

25 ينظر : اللسانيات التوليدية، غلفان: 110

26 ينظر : اللسانيات التوليدية : 110، ومباحث في اللسانيات : 246، و والنظرية اللسانية والدالة المقارنة، غاليم : 18/1 246 : 27 مباحث في اللسانيات : 28

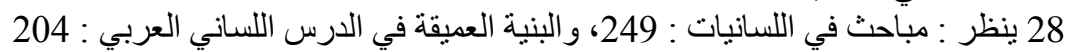
29 أهم المدارس اللسانية : 86

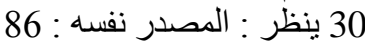
31 ينظر : أهم المدارس اللسانية: 86 32 ينظر: النحو التوليدي، قو البه النظرية وأنساقه الفرعية: 149، ومسألة المعنى في اللسانيات بين المدرسة التوزيعية

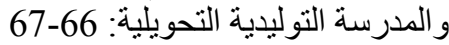
33 ينظر: الألسنية التوليدية التحويلية وقوالية اعد اللغة العربية (النظرية الألسنية): 157، واللسانيات النشأة و التطور: 231، وأهم المدارس اللسانية: 258

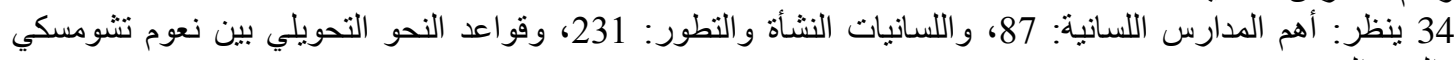
والنحو العربي: 16 35 ينظر : مناهج البحث اللغوي من هرمان باول إلى جومسكي: 278

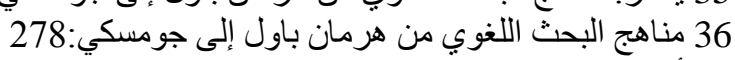
37 أهم المدارس اللسانية: 89

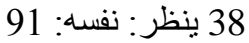

39 ينظر: النحو التوليدي: 38 ينظ 52

40 جو انب من نظرية النحو : تشومسكي: 39 41 البنية العميقة في الدرس اللساني العربي: 213 42 ينظر : النظرية الألسنية، ميثال زكريا: 159 